\title{
Performance evaluation and characterization of
} wetted soil parameters of improvised mediemitters installed in a drip irrigation tomato field

\author{
Awe G.O. ${ }^{1}$, Abegunrin T.P..$^{*}$, Ojediran J.O. ${ }^{2}$, Oyetoro O.O. ${ }^{2}$
}

\author{
${ }^{1}$ Department of Crop, Soil and Environmental Sciences, Faculty of Agricultural Sciences, Ekiti State University, Ado Ekiti, \\ Nigeria. \\ ${ }^{2}$ Department of Agricultural Engineering, Faculty of Engineering and Technology, Ladoke Akintola University of Technology, \\ Ogbomoso, Nigeria.
}

\begin{abstract}
Field study was conducted to evaluate the emission uniformity (EU), global coefficient of variation $\left(C G_{v}\right)$, emitter flow variation $\left(Q_{v a r}\right)$ and distribution uniformity $(D U)$, and determine the wetted radius $\left(r_{w}\right)$ on soil surface of improvised medi-emitters installed in a tomato field. Soil water content (SWC) at four layers was determined after different periods of irrigation. Radius of wetted soil surface was determined and predicted. Irrigation frequency had no significant effect on the average discharge rate of the medi-emitters throughout the growing cycle. Average $Q_{v a r}$ and $C G_{v}$ were significantly $(P=0.05)$ influenced by the frequency of application while the $E U$ and $D U$ did not significantly $(P=0.05)$ differ among the treatments. There were significant differences in the average values of SWC in different soil layers under the different periods of irrigation. Both the observed and calculated $r_{w}$ on the soil surface were fitted with fourth order polynomial. The model performance parameters of MAE and RMSE between the calculated and observed radii were low, indicating good prediction. Medical infusion set can successfully replace the more expensive conventional emitters for drip irrigation system.
\end{abstract}

Keywords - Medical infusion set, conventional emitters, wetted soil radius, soil water status.

\section{INTRODUCTION}

One of the advocated strategies of averting the impending water crisis is the emphasis on increased water use efficiency from the irrigation sub-sector, and one way of ensuring efficient utilization of irrigation water is for farmers to switch over from the traditional surface flooding method and adopt highly efficient irrigation system, the drip irrigation systems. The drip irrigation system has become the best method of water application that has been used globally over other irrigation systems. Drip irrigation system supplies frequent and small amounts of irrigation water at single or many points to the field surface/subsurface within the plant root zone (Decroix and Malaval 1985; Youngs et al. 1999). According to Khan et al. (2014), drip irrigation system is one of the best methods with frequent, slow application of water either directly on the land or into the crop root zone rather than the entire land surface, which ensures optimum water content in the root zone.

In Nigeria, conventional pipes and emission devices used for most of the outstanding schemes of drip irrigations, though very efficient and adequate, are imported (Awe and Ogedengbe 2011). However, the devaluation of the local currency in the international market currently being experienced has make these items to be expensive, becoming unaffordable to rural and peasant farmers who make the bulk of agricultural sector. Consequently, of an estimated 71 million hectares of arable land, only about 7 per cent is being irrigated (Muhammad-Lawal et al. 2013) with the remaining area depending on rainfall. However, the high variability and uneven temporal distribution of rainfall in recent times have made rain-fed agriculture to be under threat. It was in line of this that the FAO (2010)listed Nigeria amongst the countries that are technically unable to meet their food demands from rain-fed farming. Therefore, the search for and use of locally available materials for irrigation are now promoted with a view to increasing productivity and ensuring food security.

Recently, the concept of affordable micro-irrigation systems has been identified as a commensurate drip technology for low-income farmers and these systems have posed momentous potential for efficient agricultural water use (Mofoke et al. 2004). For example, low-cost microirrigation systems in use today include the drum and bucket drip kits (Cornish and Brabben 2001), and the Nica 
Irrigation (Anon. 2003) which apply water in pulses often more than once a day. In other to evaluate the efficiency and applicability of these systems, considerable studies have been conducted with success (e.g. Polak et al.1997; Bissrat et al.2001; Masimba 2003).

Recently too, medical infusion set, otherwise known as medi-emitter, used mainly in hospitals and clinics for transfusion purposes has been successfully adopted as emitters in drip irrigation. Mofoke et al. (2004) first used medi-emitters and reported satisfactory performance as drippers for a continuous-flow drip irrigation system installed in tomato plots in Awe and Ogedengbe (2011) employed medi-emitters in conjunction with bamboo laterals, the authors found that the locally sourced materials performed well with variation in medi-emitter discharge not more than 10.21 percent, low manufacturer's CV (3.35) and high statistical uniformity coefficient $(98.33 \%)$ and distribution uniformity (97.69\%). One shortcoming about these two studies is that the medi-emitters were calibrated to supply to the field in drops of water per minutes, in other words, they were not calibrated to supply water to the field at discharge rates that could be comparable to those of conventional emitters, therefore there is gap in knowledge on how the improvised systems perform over time.

Drip irrigation can potentially have high application efficiency and high distribution uniformity, which are very important in ensuring uniformly and high crop yields as well as preserving water quality, especially when both water and fertilizers are applied through the irrigation system. However, the uniformity and general performance of microirrigation systems are affected by several factors including manufacturer's coefficient of variation, grouping of emitters and emitter clogging, water temperature, water quality, among others (Frizzone 1997). The hydraulic of the system and topography of the field also cause variation in pressure head at individual outlet. According to Solomon (1984), as the pressure variation in drip irrigation system increases, both the uniformity and application efficiency tend to reduce, causing increase in water losses and leading to overor under-irrigation. In addition, improper maintenance of irrigation system can cause the uniformity to decrease, resulting in increased water application to compensate for decreased application uniformity or reduced yields (Sammis and $\mathrm{Wu}$ 1985). Therefore, tests to evaluate performance, related to resistance and durability of irrigation system, defined through technical specification rules are required. The aim of evaluating the operation of irrigation systems is for better understanding of the adequacy and determination of the necessary procedures required for improving the system. According to Awe and Ogedengbe (2011), such evaluation should be carried out soon after the system installation in the field and periodically repeated until harvest. This is because drip irrigation systems are sensitive to operational conditions over time (Keller and Blisner 1990; Soccol et al. 2002). Therefore, the objective of this study was to evaluate the performance and determine the wetted radius on soil surface of improvised medi-emitters installed in a tomato field under different drip irrigation frequency.

\section{MATERIALS AND METHODS}

Description of study site

The experiment was conducted at the Teaching and Research Farm of Ladoke Akintola University of Technology, Ogbomoso southwest Nigeria. The field is located on Latitude $8.168343^{\circ} \mathrm{N}$, Longitude $4.269921^{\circ} \mathrm{E}$ and Altitude $357 \mathrm{~m}$. Ogbomoso is characterized by bimodal rainfall pattern, peaking in July and September with annual rainfall depth of about $1200 \mathrm{~mm}$ (Abegunrin et al. 2013) while the mean annual maximum and minimum temperature are 33 and $28^{\circ} \mathrm{C}$, respectively. The climate is cold and dry from November to March and then warm and moist from April to October, it could also be described as a hot humid tropical which falls in southern Guinea Savannah of Nigeria with mean relative humidity of about $74 \%$ all year round except in the months of December to February when it is low as a result of dry wind (harmattan) that blows from the north (Olaniyi et al.2010), while the soil of the site is classified as Hapludalf (SSS 2006), with the textural analysis showing sandy loam texture. Some physical and chemical properties of the $0-30 \mathrm{~cm}$ layer are presented in Table 1.

\begin{tabular}{|c|c|c|c|c|c|c|c|}
\hline $\begin{array}{l}\text { Soil } \\
\text { depth, cm }\end{array}$ & $\mathrm{pH}$ & $\begin{array}{c}\text { SOM } \\
\%\end{array}$ & $\begin{array}{c}\mathrm{BD} \\
\mathrm{g} / \mathrm{cm}^{3}\end{array}$ & Sand & Silt & Clay & Texture \\
\hline $0-5$ & 7.2 & 1.8 & 1.48 & 80.5 & 8.1 & 11.4 & SL \\
\hline $5-10$ & 6.8 & 1.2 & 1.62 & 77.6 & 12.0 & 10.4 & SL \\
\hline $10-20$ & 6.6 & 1.2 & 1.70 & 79.7 & 10.1 & 10.2 & SL \\
\hline $20-30$ & 6.2 & 1.0 & 1.73 & 76.3 & 13.2 & 11.5 & SL \\
\hline
\end{tabular}

pH: level of alkalinity or acidity, SOM: soil organic matter, BD: bulk density, SL: sandy loam. 
Installation of drip irrigation system

The experiment consists of two 6500 liters capacity tanks mounted at the upper end of the field. The feeder tank was positioned $3 \mathrm{~m}$ height above ground level and connected to the supply tank with $1.5 \mathrm{~m}$ height through a PVC pipe. The feeder tank continuously feed the supply tank with water at a constant head while the supply tank consists of a floating device to regulate the height of water. The floating device helps to ensure a constant pressure in the supply tank. The supply tank was connected to the main (diameter $25 \mathrm{~mm}$ ) through a gate valve. Six laterals (made of garden hose), each $25 \mathrm{~m}$ long and diameter $15 \mathrm{~mm}$, were laid at each side of the plot with 54 medi-emitters on each laterals. Twelve (12) medi-emitters were laid on each sub-plots, 6 to each side of the laterals with spacing of $0.33 \mathrm{~m}$ (Figure 1 and Plate 1). The medi-emitters were forced into the lateral of the drip line already on the field.

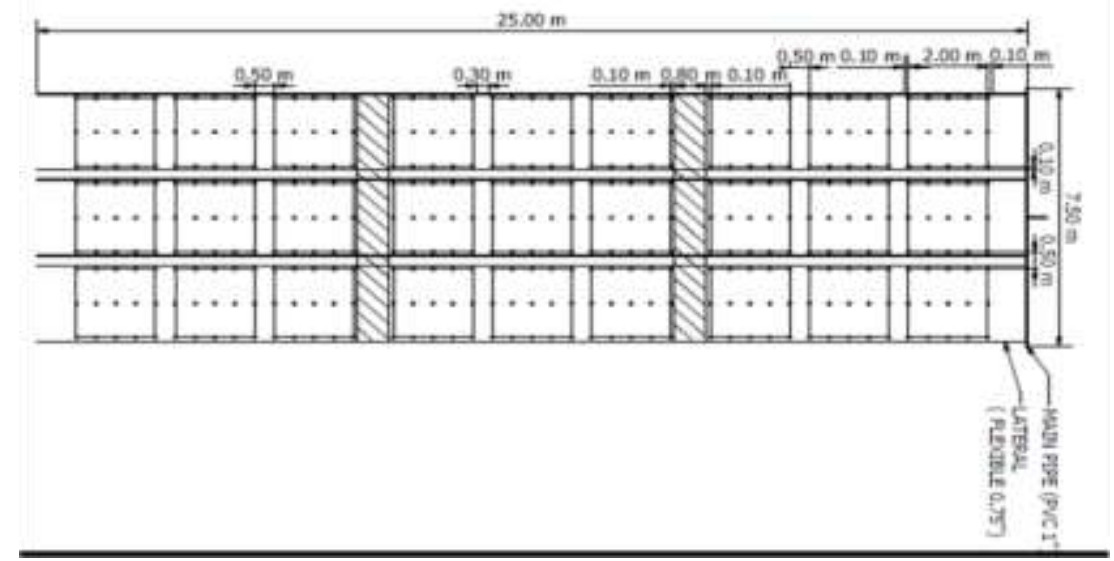

Fig.1: Experimental Field Layout

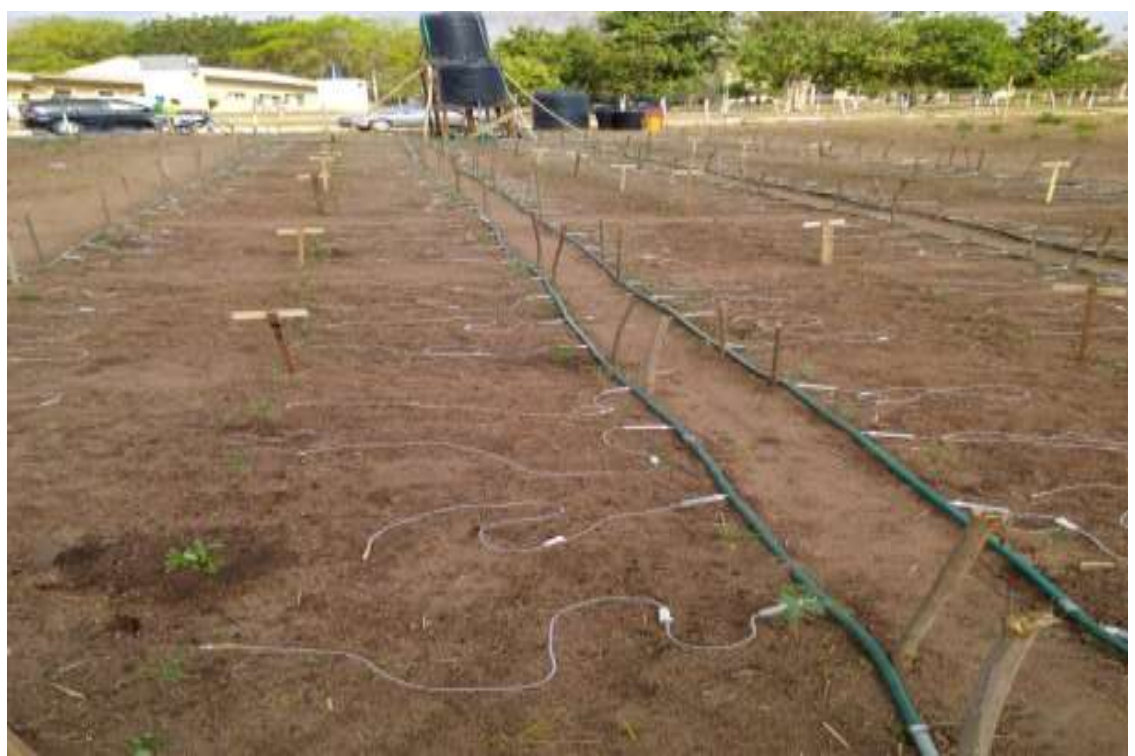

Plate.1: The drip irrigation setup showing the medi-emitters

\section{Calibration of medi-emitters}

The medi-emitters were calibrated on the field using a stop watch and a measuring cylinder of $1 L$ capacity. The mediemitters were fitted to the garden hose (laterals) while the control knobs were gradually adjusted so that water is allowed to flow to the measuring cylinder. The time taken to fill $1 L$ measuring cylinder for each trial was noted and the procedure was repeated several times until a time was reached when 1 litre was filled in 15 minutes. The position of the control knob at this point was marked. Several trials were made with the fixed position of the control knob to ensure accuracy and in each case, the discharge was $1 L$ in 15 minutes which is equivalent to $4 L / h$. 
Performance evaluation of the medi-emitter

Water discharge from the emitters was used to evaluate the performance. This involves the direct process of collecting water in a plastic container, or catch can, measuring the water using a sensitive scale and converting it to volume on the assumption that $1 \mathrm{~g}=1 \mathrm{~cm}^{3}$. The collection time was set to 10 minutes, considered enough to obtain adequate volume (ASAE EP 458 1996). The performance parameters evaluated include: emission uniformity, global coefficient of variation, emitter flow variation and distribution uniformity as described below:

(i) The Emission uniformity (EU) was determined according to the procedure of Keller and Karmeli (1974).

$$
E U=100 \times \frac{Q_{\text {min }}}{Q_{\text {ave }}}
$$

where $\mathrm{EU}=$ Field emission uniformity $(\%) ; \mathrm{Q}_{\min }=$ minimum discharge rate $(\mathrm{L} / \mathrm{h}) ; \mathrm{Q}_{\mathrm{ave}}=$ average of all field data emitter discharge rates $(\mathrm{L} / \mathrm{h})$.

(ii)The emitter flow variation $\left(Q_{v a r}\right)$ and coefficient of variation $\left(C_{v}\right)$ was according to Keller and Karmeli (1974) as:

$$
Q_{v a r}=\frac{Q_{\max }-Q_{\min }}{Q_{\max }}
$$

where $\mathrm{Q}_{\text {var }}=$ emitter flow variation $(\mathrm{L} / \mathrm{h}) ; \mathrm{Q}_{\max }=$ maximum emitter flow rate $(\mathrm{L} / \mathrm{h}) ; \mathrm{Q}_{\min }=$ minimum emitter flow rate $(\mathrm{L} / \mathrm{h})$

(iii) Coefficient of global variation $\left(C G_{v}\right)$ was calculated according to the equation

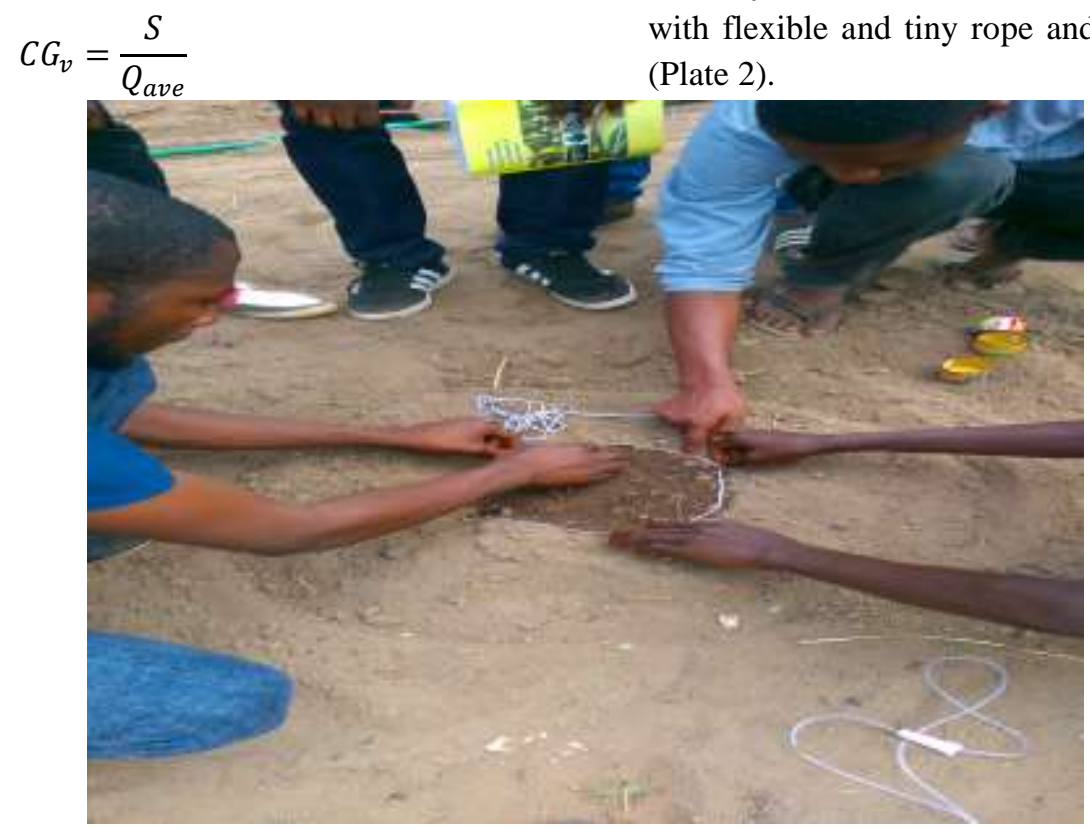

Plate.2. Determination of radius of wetted surface using planimetry method. where $\mathrm{S}=$ standard deviation of emitter flow rate $(\mathrm{L} / \mathrm{h})$; $\mathrm{Q}_{\text {ave }}=$ average emitter flow rate $(\mathrm{L} / \mathrm{h})$.

(iv) Distribution uniformity $(D U)$ was computed according to Keller and Karmeli (1974):

$$
D U=\frac{\bar{q}_{25}}{\bar{q}} * 100
$$

where DU $=$ distribution uniformity $(\%) ; \bar{q}_{25}=$ average of $25 \%$ lowest emitter rates $(\mathrm{L} / \mathrm{h}) ; \bar{q}=$ average emitter flow rate $(\mathrm{L} / \mathrm{h})$.

The performance indices were determined from spatial perspective considering all emitters in all the three drip irrigation frequency treatments after installation (a week after transplanting). These parameters were again evaluated for each treatment at mid-season and at harvest to reveal the system's change in discharge and distribution uniformity with time as suggested by Mofoke et al.(2004). The performance indices were compared with ASAE EP 405 (1985) standards for optimum operating system for drip irrigation systems.

Radius of water pool formed on the soil surface and soil water content

Twelve medi-emitters were randomly selected on the field and are numbered A1, A2, B1, B2, C1, C2, D1, D2, E1, E2 $\mathrm{F} 1$ and F2. Each of the emitter was opened to the calibrated discharge of $4 \mathrm{~L} / \mathrm{h}$. The emitters A1 and A2 were allowed to run for 15 minutes after which the knobs were closed. The wetted perimeter was measured by planimetry method, whereby the circumference of the wetted area was traced with flexible and tiny rope and the length was determined (Plate 2). 
The diameter of the approximate circle formed was calculated using the equation

$$
\text { Circumference }=\pi d
$$

where $d$ is the diameter of the circle, $\mathrm{cm}$. The radius $r$ was calculated as $r=d / 2$.

At the end each experiment, soil samples (in triplicates) were collected from the $0-10,10-20,20-30$ and $30-40 \mathrm{~cm}$ layers for the determination of gravimetric water content, $\theta_{\mathrm{g}}$. The soil volumetric water content, SWC, was computed from the product of $\theta_{\mathrm{g}}$ and bulk density, BD.

Modeling of radius of water pool formed on the soil surface In order to model the radius of circle of water entry at time ' $t$ ', it is necessary to consider the infiltration rate (Subbaiah and Mashru 2013). These authors suggested the use of Kostiakov's equation $\left(I=A t^{n}\right)$ for the cumulative depth of infiltration in any soil. To apply this equation, infiltration tests were performed before transplanting of tomato seedlings.

The radius of the water pool formed on the soil surface $\left(r_{w}\right)$ was given as:

$$
r_{w}{ }^{2}=0.955 Q / a\left[2 t^{b}+3^{b}\right]
$$

where $Q$ is the emitter flow rate $\left(\mathrm{cm}^{3} \mathrm{~min}^{-1}\right), a=A * n$ and $b=n-1$ are constants obtained from Kostiakov cumulative infiltration equation. The description of this equation can be found in Subbaiah and Mashru (2013). The calculated radii of water pool on soil surface $\left(r_{w}\right)$ were plotted against time and a regression equation was obtained. The observed and calculated $r_{w}$ values were compared using statistical parameters of mean absolute error (MAE) and root mean square error (RMSE).

\section{Statistical analysis}

Data obtained on performance evaluation and soil water content in the different layers were subjected to descriptive analysis and analysis of variance (ANOVA) at 5\% level of probability. Statistical analyses were done in SPSS (IBM version 20).

\section{RESULTS AND DISCUSSION}

Performance evaluation of the medi-emitters

The descriptive statistics of the calibrated discharge rates of the medi-emitters installed in the tomato field under drip irrigation are presented in Table 2. Irrigation water supplied to the field at different frequency had no significant effect on the average discharge rates of the medi-emitters throughout the tomato growing cycle. The discharge rates from the medi-emitters ranged between 3.73 and $4.10 \mathrm{~L} / \mathrm{h}$; 3.57 and $4.07 \mathrm{~L} / \mathrm{h}$ and 3.57 and $4.03 \mathrm{~L} / \mathrm{h}$ shortly after transplanting, mid-season and harvest, respectively for the different drip irrigation regimes, with the mean discharge rate at par $(3.91 \mathrm{~L} / \mathrm{h})$ for all treatments. The overall average calibrated discharge rate is slightly lesser (about $2.25 \%$ decrease) than the nominal discharge rate of $4 \mathrm{~L} / \mathrm{h}$ from conventional drip emitters. The maintenance of the discharge rate throughout the growth cycle made it possible for supplying water towards meeting scheduled crop water requirements of the tomato crop.

Table.2: Descriptive statistics of the discharge rate of the medi-emitters installed in the tomato field.

\begin{tabular}{lllll}
\hline & Max. & Min. & Mean & SD \\
\cline { 2 - 5 } Irrigation frequency & \multicolumn{4}{c}{ Shortly after transplanting } \\
\hline F1 & 4.03 & 3.73 & $3.91 \mathrm{a}$ & 0.083 \\
F2 & 4.03 & 3.80 & $3.92 \mathrm{a}$ & 0.054 \\
F3 & 4.10 & 3.80 & $3.92 \mathrm{a}$ & 0.062 \\
\cline { 2 - 5 } & \multicolumn{4}{c}{ Mid-season } \\
\cline { 2 - 5 } F1 & 4.07 & 3.57 & $3.89 \mathrm{a}$ & 0.103 \\
F2 & 4.07 & 3.77 & $3.93 \mathrm{a}$ & 0.067 \\
F3 & 4.00 & 3.77 & $3.90 \mathrm{a}$ & 0.067 \\
\cline { 2 - 5 } & 4.5 \\
F1 & 3.57 & $3.89 \mathrm{a}$ & 0.095 \\
F2 & 4.03 & 3.60 & $3.92 \mathrm{a}$ & 0.090 \\
F3 & 4.00 & 3.80 & $3.91 \mathrm{a}$ & 0.055 \\
\hline
\end{tabular}

F1: irrigation every 7 days; F2: irrigation every 5 days and F3: irrigation every 3 days

Means followed by the same letter did not differ significantly at 5\% level of probability by Fisher's LSD test. 
Variation in discharge

Average discharge variation $\left(\mathrm{Q}_{\text {var }}\right)$ was significantly $(\mathrm{P}=0.05)$ influenced by the frequency of water application (Table 3). Shortly after transplanting, F1 and F3 treatments had significantly higher $\mathrm{Q}_{\mathrm{var}}$ than F2 treatment. At midseason stage, F1 treatment had the significantly highest
$\mathrm{Q}_{\mathrm{var}}(12.30)$ compared with other treatments. At harvest, similar result was obtained as $\mathrm{F} 1$ had the significantly highest $\mathrm{Q}_{\mathrm{var}}$ (13.01). Except for F3 treatment, the variation in discharge increased with time.

Table.3: Performance evaluation of the medi-emitters at planting, mid-season and harvest of tomato.

\begin{tabular}{|c|c|c|c|c|}
\hline \multirow[b]{2}{*}{ Irrigation frequency } & $\mathrm{Q}_{\mathrm{var}}$ & $\mathrm{EU}$ & $C G_{v}$ & $\mathrm{DU}$ \\
\hline & \multicolumn{4}{|c|}{ Shortly after transplanting } \\
\hline $\mathrm{F} 1$ & $7.44 \mathrm{a}$ & $97.87 \mathrm{a}$ & $2.13 \mathrm{a}$ & $97.20 \mathrm{a}$ \\
\hline $\mathrm{F} 2$ & $5.79 \mathrm{~b}$ & $98.63 \mathrm{a}$ & $1.37 \mathrm{~b}$ & $98.32 \mathrm{a}$ \\
\hline \multirow[t]{2}{*}{ F3 } & $7.32 \mathrm{a}$ & $98.43 \mathrm{a}$ & $1.57 \mathrm{ab}$ & $98.11 \mathrm{a}$ \\
\hline & \multicolumn{4}{|c|}{ Mid-season } \\
\hline $\mathrm{F} 1$ & $12.30 \mathrm{a}$ & $97.35 \mathrm{a}$ & $2.65 \mathrm{a}$ & $96.55 \mathrm{a}$ \\
\hline $\mathrm{F} 2$ & $7.38 \mathrm{~b}$ & $98.30 \mathrm{a}$ & $1.70 \mathrm{~b}$ & $98.04 \mathrm{a}$ \\
\hline \multirow[t]{2}{*}{$\mathrm{F} 3$} & $5.83 \mathrm{c}$ & $98.27 \mathrm{a}$ & $1.73 \mathrm{~b}$ & $97.90 \mathrm{a}$ \\
\hline & \multicolumn{4}{|c|}{ Harvest } \\
\hline $\mathrm{F} 1$ & $13.01 \mathrm{a}$ & $97.56 a$ & $2.44 \mathrm{a}$ & $97.09 a$ \\
\hline $\mathrm{F} 2$ & $10.74 b$ & $97.70 \mathrm{a}$ & $2.30 \mathrm{a}$ & $97.05 a$ \\
\hline F3 & $5.00 \mathrm{c}$ & $98.59 a$ & $1.41 \mathrm{~b}$ & $98.26 a$ \\
\hline
\end{tabular}

F1: irrigation every 7 days; F2: irrigation every 5 days and F3: irrigation every 3 days

Means followed by the same letter did not differ significantly at 5\% level of probability by Fisher's LSD test.

The significantly higher and increase in Qvar over time obtained from $\mathrm{F} 1$ and $\mathrm{F} 2$ treatments are attributed to certain phenomena taking place during the period ( 7 and 5 days, respectively) which the medi-emitters remained closed. For example, there may have been accumulation of dirts at the close point, causing partial plugging or the difficulty of the light hose to fully open as a result of elastic behaviour of the material. Thus, each time the emitters are reopened, about 2-3 minutes are needed before the system stabilizes, thus the higher variability. Mofoke et al. (2004) stated that the general variability in discharge could be attributed to major and minor losses occurring at the delivery pipe joints and fittings right from the supply tank to the emitters (e.g. inherent leakages at the point of immersion of emitters to the main line).

\section{Coefficient of global variation}

The coefficient of global variation $\left(C G_{v}\right)$ in discharge describes the quality of the processes used to manufacture emission devices. The coefficient of global variation was significantly $(\mathrm{P}=0.05)$ affected by the frequency of water application. At the different periods of evaluation, the mediemitters installed in F1 treatment had the significantly highest $C G_{v}$ (Table 3). The average values of $C G_{v}$ were www.ijeab.com generally low (not more than 2.65) and according to American Society of Agricultural Engineering (ASAE EP 1985) recommended classification of coefficient of global variation in discharge, these values are below the $10 \%$ threshold as 'good' for point source emitters. This showed that the adopted medical infusion set (medi-emitters), coupled with mechanism to control flow rate, can be employed as substitute for the conventional drippers for drip irrigation systems. This result agrees with the findings of Mofoke et al.(2004) and Awe and Ogedengbe (2011) on the adoption of medical infusion set as drip emitters.

\section{Emission and distribution uniformity}

Emission uniformity (EU) describes how evenly an irrigation system distributes the same depth of water to every unit area. On the other hand, distribution uniformity (DU) is an indicator of the magnitude of the system's distribution problems. Although F1 treatment had the lowest values (about 97\%) of the uniformity coefficients, but they did not significantly differ from other treatments. According to the classification of irrigation system performance by ASAE EP 405 (1985), an EU rating of 90 $95 \%$ is considered excellent and the system would only require regular maintenance, while a DU of $85 \%$ or greater 
is considered excellent. In this study, the average values of both EU and DU monitored at different stages of the tomato growth cycle were above the maximum threshold for microdrip irrigation system, indicating that the system performance was excellent. The high EU and DU values followed the trend of observed low coefficient of global variation in discharge $\left(\mathrm{CG}_{\mathrm{v}}\right)$. The lower $\mathrm{EU}$ and $\mathrm{DU}$ obtained from $\mathrm{F} 1$ treatment is attributed to higher $\mathrm{CG}_{\mathrm{v}}$ observed. These findings also agree with previous studies (Mofoke et al. 2004; Awe and Ogedengbe 2011). The EU values obtained are also comparable to those of Manisha et al. (2015) who studied the performance evaluation of conventional drip irrigation system at discharge rate of 4 $\mathrm{L} / \mathrm{h}$.

Spatio-temporal distribution of profile soil water content The temporal variability of soil water content of the tomato field during the performance evaluation of the mediemitters is presented in Fig 2.

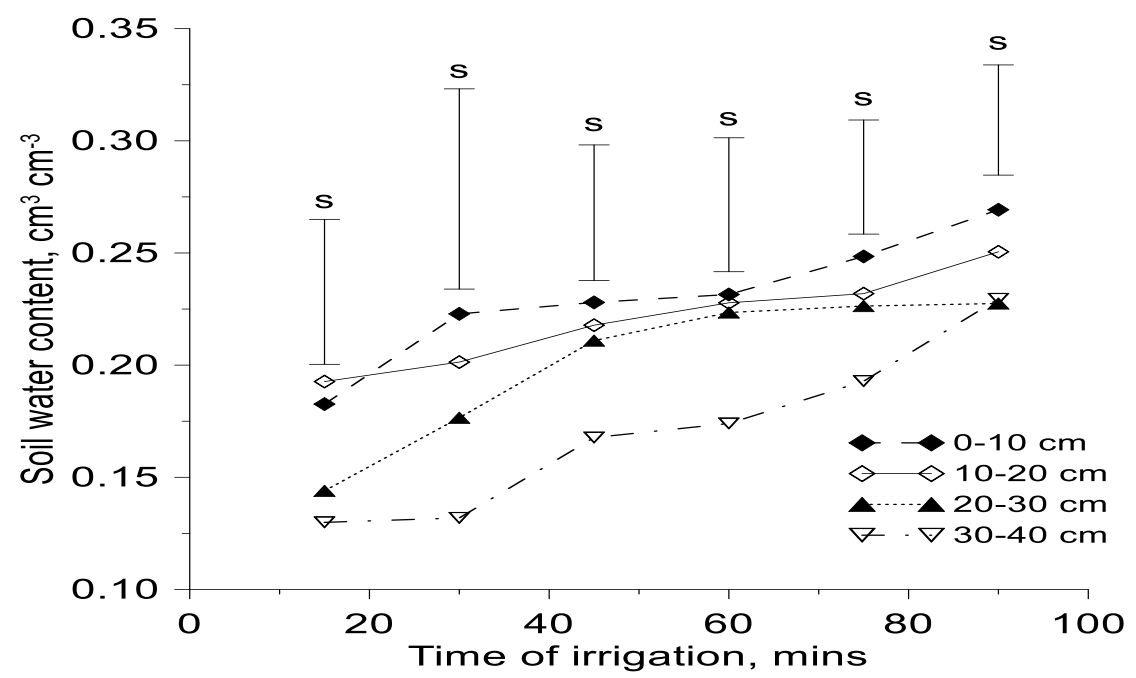

Fig.2: Temporal distribution of soil water content of the tomato field during the performance evaluation test of the medi-emitters. The vertical bars are the standard error s: significant at 5\% level of probability by Fisher's least significant difference test.

There were significant differences in the average SWC in the different soil layers under the different time of irrigation, with the $30-40 \mathrm{~cm}$ layer having the lowest SWC at all times. As expected, the SWC of each soil layer increases with time, with the $10-20 \mathrm{~cm}$ layer having the lowest amplitude while the $30-40 \mathrm{~cm}$ layer had the highest amplitude. The amplitude of the $0-10 \mathrm{~cm}$ surface layer was high compared to that of $10-20 \mathrm{~cm}$ layer. The high amplitude in the surface layer is attributed to evaporation since it is the layer that is exposed to the atmosphere. The SWC of the $0-10 \mathrm{~cm}$ surface layer was about $28.9 \%$ greater than that of 30-40 cm layer when irrigated for 15 minutes. However, at the end of 90 minutes of irrigation, the $0-10 \mathrm{~cm}$ surface layer had SWC higher than that of 30-40 cm layer by $14.6 \%$, about half reduction. The high amplitude and high percent difference in the SWC of 30-40 cm layer at the initial stage compared with the surface layer is attributed to relative dryness in the subsurface layer when the evaluation was conducted, during this time, very few centimeters from the soil surface have been wetted (Fig 3). On the other hand, the rapid reduction in the gap between the SWC of the surface and subsurface layer at the end of 90 minutes is attributed to high water percolation and redistribution, in other words, high advance of wetting front in the soil matrix due to the sandy nature of the soil. Sandy-textured soils have greater macropores which facilitate rapid water movement and redistribution. The advance of the wetting front within the soil profile can be seen in the spatial distribution map shown in Fig 3. 

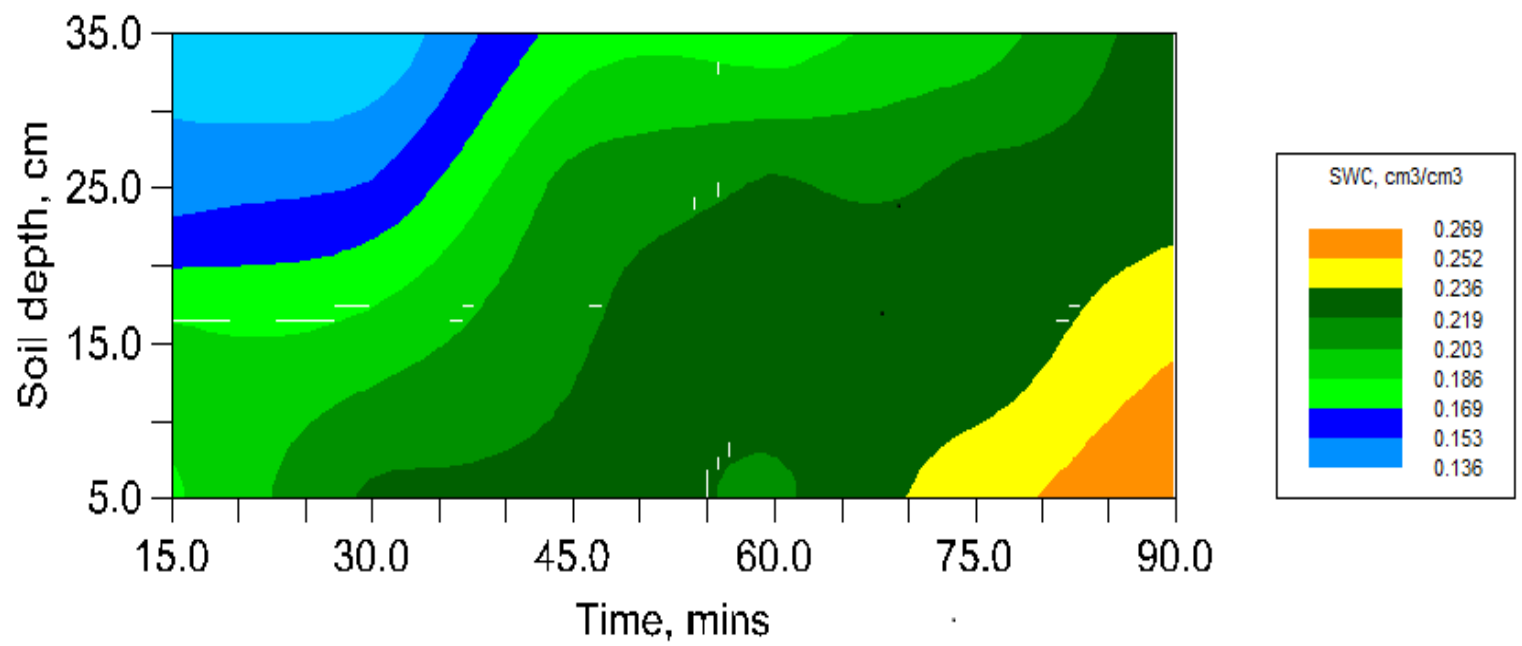

Fig.3: Spatial map showing the wetting front in the soil profile with time during the performance evaluation of the medi-emitters.

Cumulative infiltration and radius of water pool formed on the soil surface

The cumulative infiltration function of the tomato field shortly after installation of the drip irrigation system is shown in Fig 4.

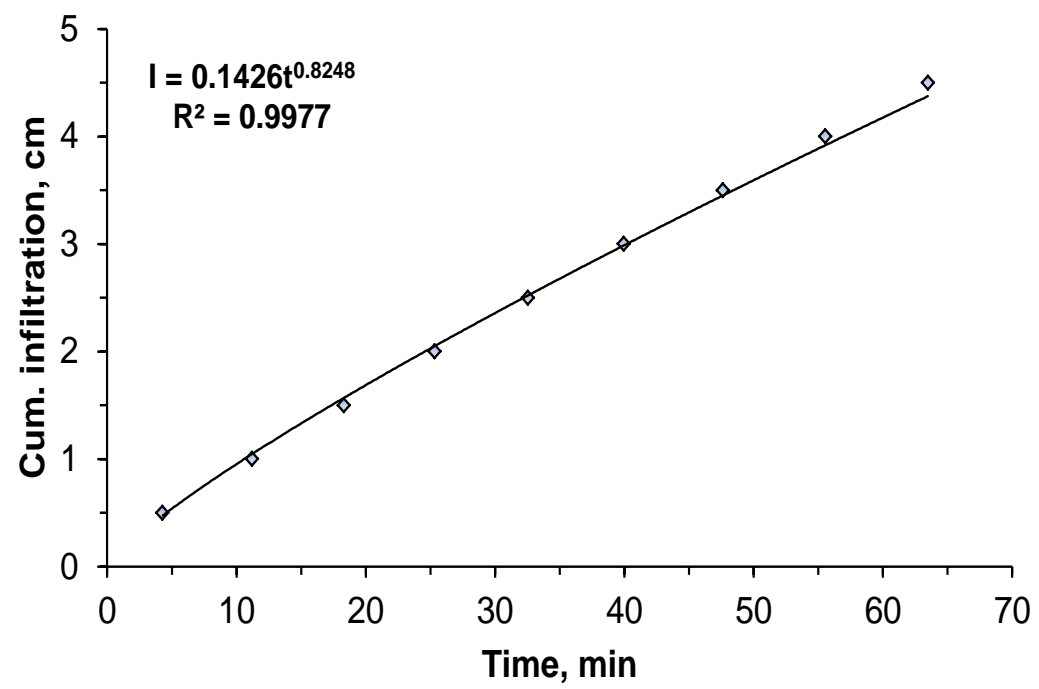

Fig.4: Cumulative infiltration of the field before the installation of the drip irrigation system.

The total cumulative infiltration was found to be about 50 $\mathrm{cm}$. There was near perfect $\left(\mathrm{R}^{2}=0.9977\right)$ goodness of fit between the observed cumulative infiltration values and the Kostiakov model. For this soil, the model constants for the radius of the water pool on the soil surface, $r_{w}{ }^{2}=$ $0.955 Q / a\left[2 t^{b}+3^{b}\right]$, $a$ was 0.1176 while $b$ was -0.1752 .

The radius of wetted soil volume is an important parameter when deciding spacing between emitters for a given set of soil and crop conditions. It also a vital component in optimizing emitter spacing based on the geometry of the wetted soil volume and in the determination of length of laterals (Subbaiah and Mashru 2013). The temporal distribution of observed and calculated wetted radii on the soil surface by the medi-emitters is shown in Figure 5. 


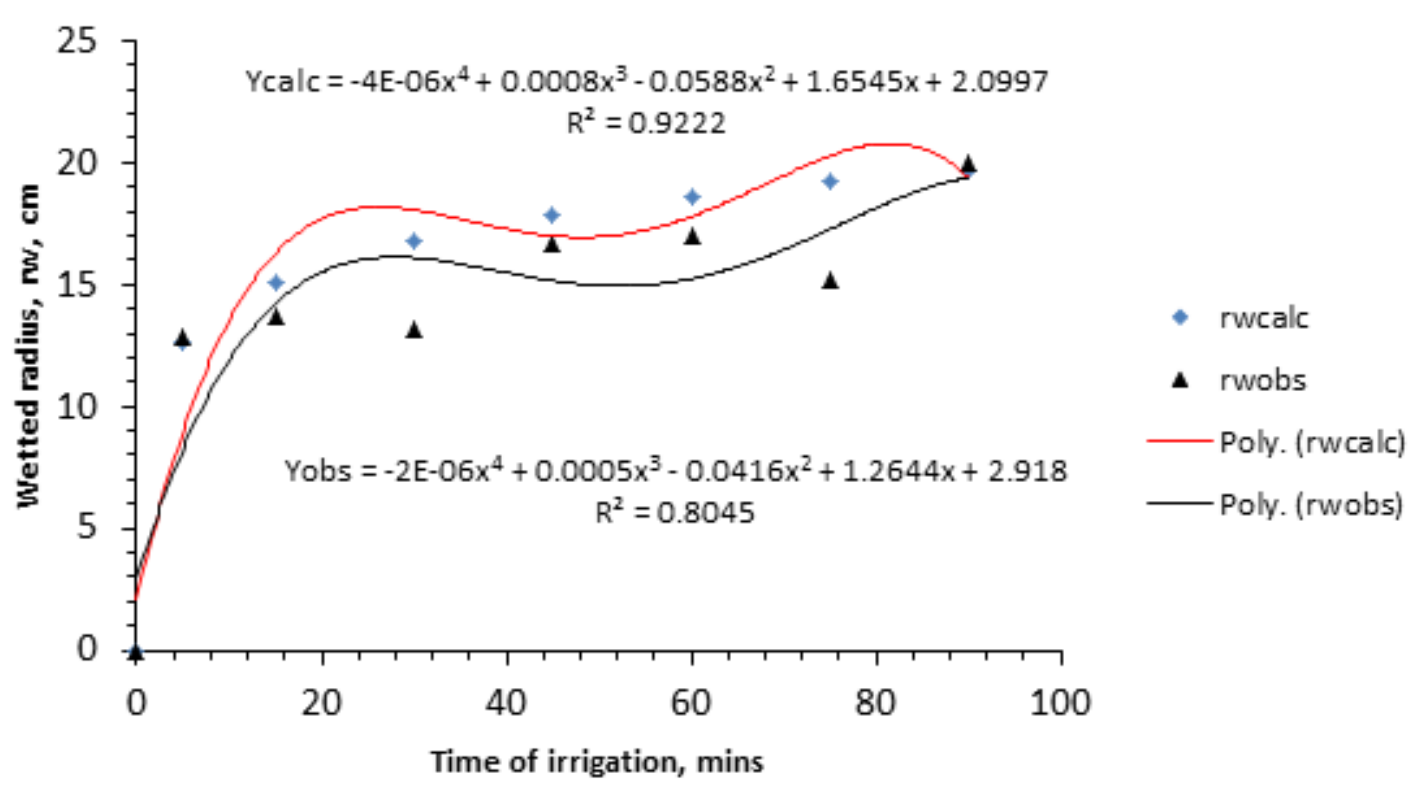

Fig.5: Calculated and observed wetted radius of the soil surface by the medi-emitters.

Increased duration of irrigation increased the wetted radius, in other words, the radial area of ponded water develops in the vicinity of the medi-emitters and expands with time. Both the observed and calculated radius of water pool on the soil surface as a function of time was fitted well with fourth order polynomial as also obtained by Subbaiah and Mashru (2013) who modeled the effect of three discharge rates on soil wetted radius of a point source surface trickle irrigation. The goodness of fit was 0.9222 and 0.8045 for the calculated and observed radii, respectively. These values were lower than those obtained by Subbaiah and Mashru (2013) who employed conventional drippers compared to the improvised medi-emitters used for this study.

In addition to goodness of fit, model validation parameters of mean absolute error (MAE) and root mean square error (RMSE) were used to compare observed and calculated $r_{w}$ values and they were 0.2258 and 0.2573 , respectively. The MAE shows the bias while the RMSE is an indication of the prediction accuracy (Chai and Draxler 2014). These values were low, indicating good prediction. In this study, only a single emitter discharge rate was evaluated, therefore we recommend further studies to include the effect of different medi-emitter discharge rates on wetted radius on the soil surface as well as depth of water pool in the subsurface. Nevertheless, this model can be used to determine the geometry of wetted bulb from surface drippers, whether conventional or improvised, for any operating discharge rate for a specific duration.

\section{CONCLUSIONS}

The discharge rate of the medi-emitters did not vary throughout the tomato growing cycle and was almost at par compared to that of conventional emitter. According to American Society of Agricultural Engineering (ASAE 1985) recommendation, the evaluated parameters showed that the system performance was excellent. The different periods of irrigation significantly influenced the average values of SWC in the different soil layers. The model performance parameters of goodness of fit, MAE and RMSE between the calculated and observed radii showed that the mathematical model can be used to predict the radius of wetted soil surface under any surface drip irrigation system. The results of the study showed that the medical infusion set, with locally produced polyvinyl chloride pipes (PVC), can successfully replace the more expensive conventional emitters and delivery pipes for drip irrigation system. However, we recommend further studies to include the effect of different discharge rates on wetted radius on the soil surface as well as depth of water pool in the subsurface.

\section{REFERENCES}

[1] Abegunrin TP, Awe GO, Idowu DO, Onigbogi OO Onofua OE (2013) " Effect of kitchen wastewater on soil properties and growth parameters of cucumber (Cucumis sativus)', Journal of Soil Science and Environment. 4(7): 139145.doi:10.5897/JSSEM2013.0412 
[2] Anon (2003). Smart Water Solutions: examples of innovative, low-cost technology for wells, pumps, storage, irrigation and water treatment. - Netherlands Water Partnership (NWP). Delft, the Netherlands.

[3] ASAE- American Society of Agricultural Engineers (1985) Design, installation and performance of trickle irrigation systems, EP 405, pp.508.

[4] ASAE- American Society of Agricultural Engineers. (1996). Field evaluation of micro-irrigation systems, EP 458, 792-797.

[5] Awe GO, Ogedengbe K (2011) Performance evaluation of bamboo (Bambusa vulgaris Schrad)-pipe and medi-emitter in a gravity-flow drip irrigation system. Int. J. Agric. For., 1(1): 9-13.

[6] Bissrat G, Asghedom S, Mehari A (2001) Affordable micro-irrigation technology (AMIT). In: Eritrea Prefeasibility study report, March-September 2001. Report of a consultative project between the Centre for Development and Environment (CDE), University of Bern, International Development Enterprises (IDE) and the College of Agriculture and Aquatic Science (CAAS), University of Asmara.

[7] Chai T, Draxler RR (2014). Root mean square error (RMSE) or mean absolute error (MAE)? Arguments against avoiding RMSE in literature. Geosic. Model Dev., 7: 1247-1250.

[8] Cornish G, Brabben T (2001) Field guide on irrigated agriculture for field assistants. International programme for technology and research in irrigation and drainage. FAO, Rome.

[9] Decroix M, Malaval A (1985) Laboratory evaluation of trickle irrigation equipment for field system design. Proceedings of the third International Drip/Trickle Irrigation Congress, Volume I, California, USA. pp. 325-338.

[10]FAO (2010) FAOSTAT Production Yearbook 2010.

[11] Frizzone JA (1997) Uniformidade e eficiencia da irrigacao. Departmento de Engenharia Rurual, ESALQ, Serie didatica, Piracicaba. 2-18.

[12] Keller J, Blisner RD (1990) Sprinkler and trickle irrigation. Van Nostrand Reinhold, New York. Pp 427602.

[13] Keller J, Karmeli D (1974) Trickle irrigation design parameters. Transaction of ASAE, 7, 687-684.

[14] Khan GD, Ali A, Akbar F (2014) Assessment of coefficient of variation of emitters flow rate with respect to design, manufacturers and plugging in installed drip irrigation systems at selected sites of Peshawar valley. Adv. Life Sci. Tech., 19: 27-32.
[15] Manisha I, Sinha J, Tripathi MP (2015) Studies on hydraulic performance of drip irrigation under operating pressure. Int. J. Appl. Eng. Tech., 5(2): 1-6.

[16] Masimba B (2003) Drip irrigation helps smallholders. - In: "African Farming and Food Processing" July/August 2003 edition. (J. Phelan ed.). Alain Charles Publishing Ltd. London.

[17] Mofoke ALE, Adewumi JK, Mudiare OJ, Ramahan AA (2004) Design, construction and evaluation of an affordable continuous - flow drip irrigation system. Journal of Applied Irrigation Science. 39(2): 253-269.

[18] Muhammad-Lawal A, Adenuga AH, Jimoh O (2013). Determinants of adoption irrigation technology by small-holder farmers is selected Local Government Areas in Kwara State, Nigeria. Taraba Journal of Agricultural Research, 1(1): 21-27.

[19] Olaniyi JO, Akanbi WB, Adejumo TA, Akande OG (2010). Growth, fruit yield and nutritional quality of tomato varieties. Afric. J. Food Sci., 4(6): 398-402.

[20] Polak P, Bob N, Deepak A (1997): A low cost drip irrigation system for small farmers in developing countries. Journal of Applied Irrigation Science. 32(1), 105-112.

[21] Sammis TW, Wu IP (1985) Effect of drip irrigation design and management on fruit trees yield. Transactions of the ASAE American Society of Agricultural Engineers. 28(3): 832-838.

[22] Soccol OJ, Ullmann MN, Frizzone JA (2002) Performance analysis of a trickle irrigation subunit installed in apple orchard. Brazilian Archives of Biology and Technology. 45(4): 525-530.

[23] Soil Survey Staff (SSS) (2006). Keys to soil taxonomy. 10th ed. Washington, USDA-SCS, P. 332.

[24] Solomon KH (1984) Yield related interpretations of irrigation uniformity and efficiency measures. Irrig. Sci. 5:161-172.

[25] Subbaiah R, Mashru HH (2013) Modeling for predicting soil wetting radius under point source surface trickle irrigation. Agric. Eng. Int.: CIGR Journal, 15(3): 1-10.

[26] Youngs EG, Leeds-Harrison PB, Alghusni A (1999) Surface pounding of coarse-textured soils under irrigation with a line of surface emitters. J. Agric. Eng. Res., 73: 95-100. 